\title{
The thermal sigmatropic isomerization of pseudosaccharyl crotyl ether
}

\author{
L.I.L. Cabral $^{\text {a }}$, T.M.R. Maria ${ }^{\mathrm{b}}$, L. Martelo ${ }^{\mathrm{b}}$, M.E.S. Eusébio ${ }^{\mathrm{b}}$, M.L.S. Cristiano ${ }^{\mathrm{a}, *}$, R. Fausto $^{\mathrm{b}, *}$ \\ ${ }^{a}$ CCMAR and Department of Chemistry and Pharmacy, F.C.T. University of Algarve, P-8005-039 Faro, Portugal \\ ${ }^{\mathrm{b}}$ Department of Chemistry, University of Coimbra, P-3004-535 Coimbra, Portugal
}

\section{A R T I C L E I N F O}

Article history:

Received 13 July 2012

Received in revised form 15 October 2012

Accepted 19 October 2012

Available online 15 November 2012

\section{Keywords:}

Saccharin

3-(E)-(But-2-enoxy)-1,2-benzisothiazole

1,1-dioxide

Sigmatropic rearrangement

Infrared spectroscopy

DSC

Thermomicroscopy

\begin{abstract}
A B S T R A C T
The thermally induced sigmatropic isomerization of the pseudosaccharyl crotyl ether, 3-(E)-but-2enoxy)-1,2-benzisothiazole 1,1-dioxide (CBID), has been investigated by using temperature dependent infrared spectroscopy, differential scanning calorimetry (DSC), and polarized light thermomicroscopy. The reaction can take place in both melted and crystalline phases, affording the product resulting from the $\left[3,3^{\prime}\right]$ migration of the allylic system from $\mathrm{O}$ to $\mathrm{N}, 2-(E)-1$-methylprop-2-en-1,2-benzisothiazol-3(2H)one 1,1-dioxide (CBIOD). In the melt, the activation energy of the process was determined as being $49.1 \pm 5.3 \mathrm{~kJ} \mathrm{~mol}^{-1}$, with $k=(22.2 \pm 0.6) \times 10^{4} \mathrm{~s}^{-1}$ at $140{ }^{\circ} \mathrm{C}$. In the solid state, at $110{ }^{\circ} \mathrm{C}$, the rate constant drops by one order of magnitude $\left[k=(1.46 \pm 0.07) \times 10^{4} \mathrm{~s}^{-1}\right]$. The enthalpy of reaction, determined by DSC, is $\Delta_{\mathrm{rx}} \mathrm{H}=-27.0 \pm 0.8 \mathrm{~kJ} \mathrm{~mol}^{-1}$. Assignments were proposed for the infrared spectra of the observed neat condensed phases of the two compounds.
\end{abstract}

(c) 2012 Elsevier Ltd. All rights reserved.

\section{Introduction}

Benzisothiazoles, also known as pseudosaccharins, have important applications in major areas. In food chemistry, saccharin (1,2benzisothiazol-3-one 1,1 dioxide) is the oldest artificial sweetener, and saccharyl derivatives are used in agriculture, as herbicides, fungicides, and pesticides. ${ }^{1,2}$ In medicine, some saccharyl derivatives are found to act as antibacterial agents, ${ }^{3}$ phospholipase, and human leukocyte elastase inhibitors, ${ }^{4-6}$ selective blockers of the estrogen receptor, ${ }^{7}$ and antiviral agents against retroviruses (e.g., HIV). ${ }^{8}$

The benzisothiazole system has strong electron-withdrawing properties, finding important uses in synthesis as a derivatizing agent. As such, saccharyl ethers may be used as intermediate compounds for reductive cleavage of the $\mathrm{C}-\mathrm{O}$ bond in phenols, and benzyl- and naphthyl alcohols. ${ }^{9-11}$

Much of the reactivity of saccharyl ethers can be ascribed to the relative $\mathrm{C}-\mathrm{O}$ bond lengths in the central $\mathrm{C}_{\mathrm{HAR}}-\mathrm{O}-\mathrm{C}_{\mathrm{A}}$ linkage (HAR=heteroaromatic ring and $\mathrm{A}=$ alkyl, allyl, benzyl, naphthyl or aryl group). The electron density on the oxygen is delocalized toward the saccharyl system and these electronic changes lead to a molecular structure in which the originally strong $C_{A}-O$ bond lengthens, becoming easily cleavable. When allyl- or alkyl-

\footnotetext{
* Corresponding authors. E-mail addresses: mcristi@ualg.pt (M.L.S. Cristiano), rfausto@ci.uc.pt (R. Fausto).
}

pseudosaccharyl ethers are heated neat or in solution, the original $\mathrm{C}-\mathrm{O}$ bond in the alcohol may cleave, while the $\mathrm{C}_{\mathrm{HAR}}-\mathrm{O}$ bond becomes a double bond, affording the corresponding $N$-allyl- or $\mathrm{N}$-alkyl-benzisothiazolones through Cope- or Chapman-like isomerizations, respectively. ${ }^{12-17}$

The thermal isomerization of 3-methoxy-1,2-benzisothiazole 1,1-dioxide has been addressed recently. ${ }^{16}$ It was shown that its Chapman-type conversion into 2-methyl benzisothiazol-3-one 1,1dioxide occurs in the melted phase and also in the crystalline phase. The mechanism was investigated, on the basis of X-ray diffraction analysis and computational models. ${ }^{17}$ Results pointed to an energetic preference for a 'quasi-simultaneous' intermolecular [1,3']transfer of methyl over an intramolecular mechanism. ${ }^{17}$

On the other hand, results of an investigation on the thermal rearrangement of a series of 3-allyloxybenzisothiazoles in the melted phase and in solution (toluene or ethanol) ${ }^{12-15}$ indicated that migration of the allyl group from $\mathrm{O}$ to $\mathrm{N}$ may afford the products of $\left[1,3^{\prime}\right]$ - and $\left[3,3^{\prime}\right]$-sigmatropic isomerizations, the relative proportion of each product depending on various factors: structure of the allyl system (effect of substitution on the allylic moiety), polarity of the reaction medium, temperature, and time of reaction. The thermal behavior of the studied 3-allyloxybenzisothiazoles contrasts with that observed for allyloxytetrazoles, ${ }^{14,18-21}$ known to afford exclusively the $\left[3,3^{\prime}\right]$-isomers when heated, through a concerted mechanism similar to the symmetry-allowed general Cope rearrangement. ${ }^{22,23}$ For the allylsaccharyl ethers, it may be proposed that the $\left[3,3^{\prime}\right]$-isomers result from a concerted sigmatropic 
rearrangement, similar to that observed for allyloxytetrazoles. On the other hand, the [1,3']-isomers could result from a fragmentationrecombination mechanism or, alternatively, from an allowed concerted pseudopericyclic process similar to that observed in the rearrangement of allylic esters. ${ }^{24,25}$ Thus, there are still many open questions regarding the isomerization of allylsaccharyl ethers, which require further investigation.

Recently, we reported results of an investigation on the thermal isomerization of 3-(allyloxy)-1,2-benzisothiazole 1,1-dioxide ${ }^{15}$ based on a concerted methodological approach, in which temperature dependent infrared spectroscopy, differential scanning calorimetry, and polarized light thermomicroscopy were used, complemented by theoretical methods. For this unsubstituted allylsaccharyl ether, results indicated that thermal isomerization occurs only above the melting point of the reactant $\left(140.0 \pm 0.1{ }^{\circ} \mathrm{C}\right)$ and that the reaction obeys first order kinetics, showing single exponential decay isotherms, with an activation energy of $92.2 \pm 1.1 \mathrm{~kJ} \mathrm{~mol}^{-1}$. Based on these data, we proposed a concerted-type mechanism, consistent with a sigmatropic reaction notionally similar to the symmetry-allowed general $\left[3,3^{\prime}\right]$-Cope rearrangement.

We now present and discuss our recent findings regarding the mechanism of thermal isomerization of neat pseudosaccharyl crotyl ether 3-(E)-(but-2-enoxy)-1,2-benzisothiazole 1,1-dioxide (CBID, see Scheme 1), using a similar methodological approach to that used for allyl pseudosaccharyl ether. ${ }^{15}$ CBID bears a methyl substituent on the allylic system that may stabilize a putative transition state with a cationic or partially positive allylic moiety. Moreover, contrarily to the previously studied unsubstituted allyl analogue, ${ }^{15}$ the products of $\left[1,3^{\prime}\right]$ and $\left[3,3^{\prime}\right]$ isomerizations in CBID are structurally different, allowing to examine the relative importance of these two processes.

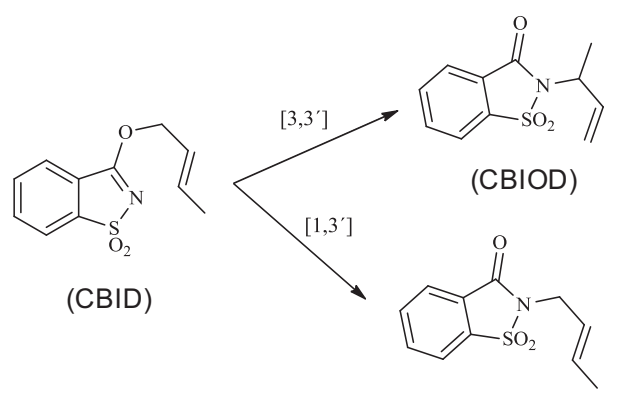

Scheme 1. Structures of 3-(E)-but-2-enoxy-1,2-benzisothiazole 1,1-dioxide (CBID; left) and its $N$-allyl isomers, 2-(E)-1-methylprop-2-en-1,2-benzisothiazol-3(2H)-one 1,1dioxide (CBIOD; right top) and 2-(E)-1-but-2-enyl-1,2-benzisothiazol-3(2H)-one 1,1dioxide (right bottom).

\section{Results and discussion}

\subsection{Infrared spectroscopy experiments}

The structure of CBID has been studied by X-ray crystallography. ${ }^{12}$ As it is in general found for saccharyl ethers, the $\mathrm{C}-\mathrm{O}$ bonds in the central $\mathrm{C}-\mathrm{O}-\mathrm{C}$ fragment are unequal in length. The bond to the carbon of the saccharyl system is unusually short $(1.314 \AA)$, with a double-bond character of $1.56,{ }^{26}$ and the bond to the carbon of the allylic system is stretched (1.488 $\AA$; bond order of 0.9 ) when compared to a normal aliphatic $\mathrm{C}-\mathrm{O}$ bond $\left(1.43 \AA^{27}\right)$. In this context, the thermally induced cleavage of this latter bond is not surprising, being consistent with Bürgi and Dunitz' approach. ${ }^{28}$ In solution, results have shown that isomerization affords the $\mathrm{N}$-allyl isomers shown in Scheme 1 in relative proportions that depend on the reaction conditions. ${ }^{13}$

The room temperature infrared spectrum of crystalline CBID is shown in Fig. 1 (Experimental section). The spectrum resembles

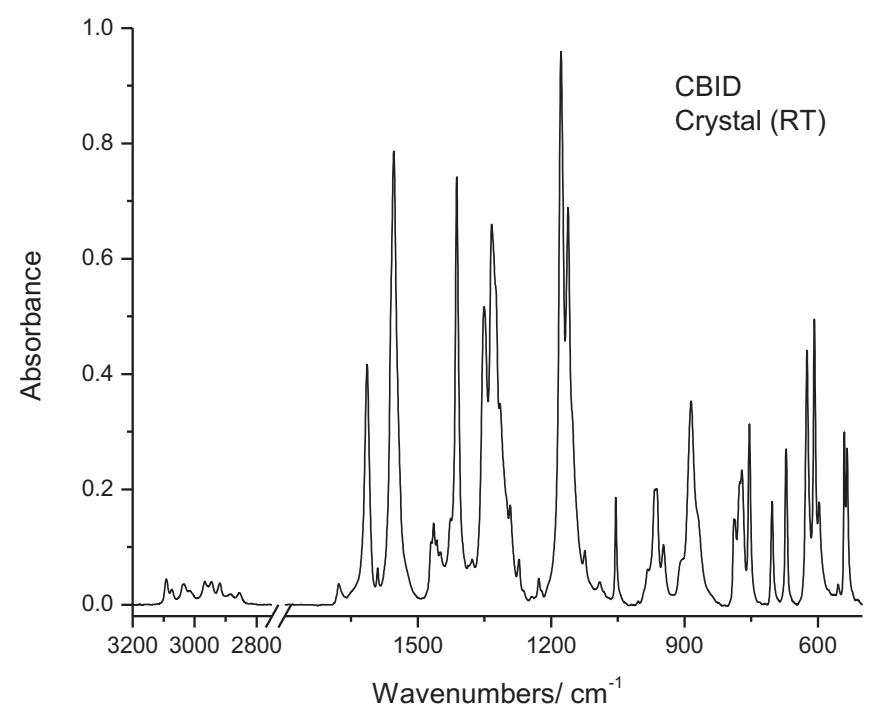

Fig. 1. Room temperature infrared spectrum of CBID (crystalline phase in a $\mathrm{KBr}$ pellet).

very much that previously reported for the non-substituted allylic parent compound, ${ }^{15,29,30}$ with very characteristic bands at 1677 $(\nu \mathrm{C}=\mathrm{C}), 1614(\nu \mathrm{CC}$, benzene ring $), 1554(\nu \mathrm{C}=\mathrm{N}), 1412\left(\nu \mathrm{C}_{\mathrm{HAR}}-\mathrm{O}\right)$, $1351\left(\nu \mathrm{SO}_{2}\right.$ as.), and $1179\left(\nu \mathrm{SO}_{2}\right.$ S.) $\mathrm{cm}^{-1}$, in the region of higher spectral intensity. The proposed assignments for the full set of observed bands are provided in Table S5 (Supplementary data).

The thermal isomerization of CBID was followed by infrared spectroscopy at different temperatures. Above the melting point $\left(\sim 130^{\circ} \mathrm{C}\right)$ of the compound, fast spectral changes were observed, with the bands of CBID reducing intensity while a new set of bands emerge. The new set of bands include the intense bands at 1731, $1253,1162,1113,997,987$, and $972 \mathrm{~cm}^{-1}$, which are ascribable, respectively, to the $\nu \mathrm{C}=\mathrm{O}, \nu(\mathrm{C}-\mathrm{N}$, heteroaromatic ring $), \mathrm{w}\left(=\mathrm{CH}_{2}\right)$, $\nu \mathrm{C}-\mathrm{C}\left(\mathrm{H}_{3}\right), \nu(\mathrm{N}-\mathrm{S}$, heteroaromatic ring), and $\nu \mathrm{N}-\mathrm{C}$ vibrational modes of the expected product of $\left[3,3^{\prime}\right]$ isomerization of CBID, 3-(E)-but-2-enoxy-1,2-benzisothiazole 1,1-dioxide (CBIOD; see Scheme 1). The full list of product bands is given in Table S6, together with the proposed assignments (Supplementary data). All emerging bands follow the same pattern of intensity growing with time, clearly indicating that a single product was formed. The evolution of the reaction with time for $T=140{ }^{\circ} \mathrm{C}$, as probed spectroscopically $\left(1800-1200 \mathrm{~cm}^{-1}\right.$ region) is shown in Fig. 2

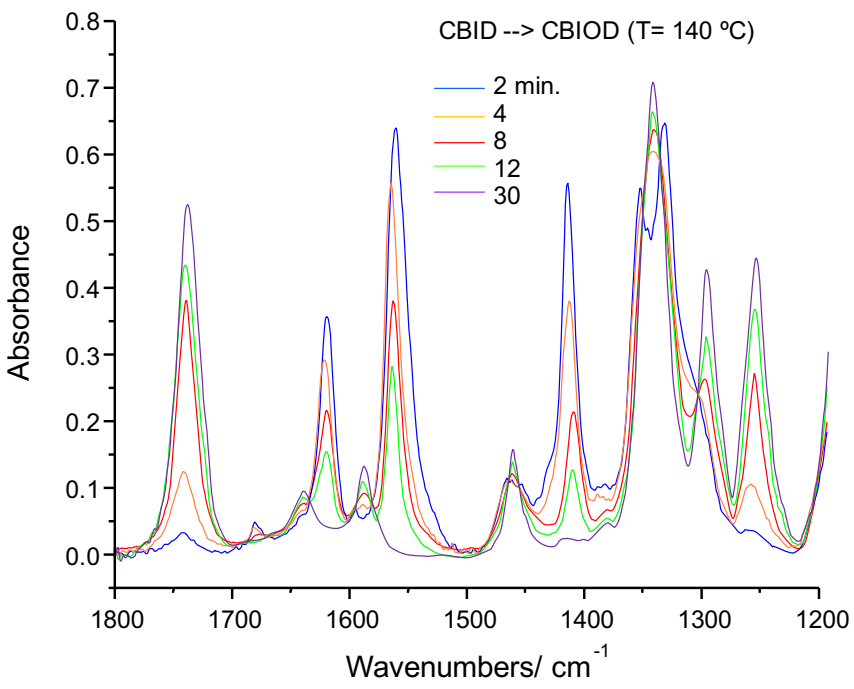

Fig. 2. Infrared spectra showing the thermal isomerization of CBID into CBIOD (spectra obtained at different times of reaction in a $\mathrm{KBr}$ pellet kept at $140{ }^{\circ} \mathrm{C}$ ). 
(Experimental section), the spectra therein shown presenting the expected isosbestic points, in agreement with a single reactant to product conversion. The kinetic curves for the observed isomerization reaction, obtained at different temperatures, are given in Fig. 3. This figure shows the normalized (to unity) IR intensity decays determined from the integrated intensities of the bands in the $1640-1500 \mathrm{~cm}^{-1}$ wavenumber range and around $1412 \mathrm{~cm}^{-1}$, ascribed to CBID. The obtained kinetic curves correspond to single exponential decays, in agreement with the occurrence of a single process of intramolecular nature (see Table 1, for obtained rate constants). In this regard, the present results differ from those observed in solution, using toluene or ethanol, where both $\left[1,3^{\prime}\right]$ and $\left[3,3^{\prime}\right]$ rearrangements were shown to take place simultaneously, with the $\left[1,3^{\prime}\right]$ mechanism being favored by the polarity of the medium and the temperature. ${ }^{13}$

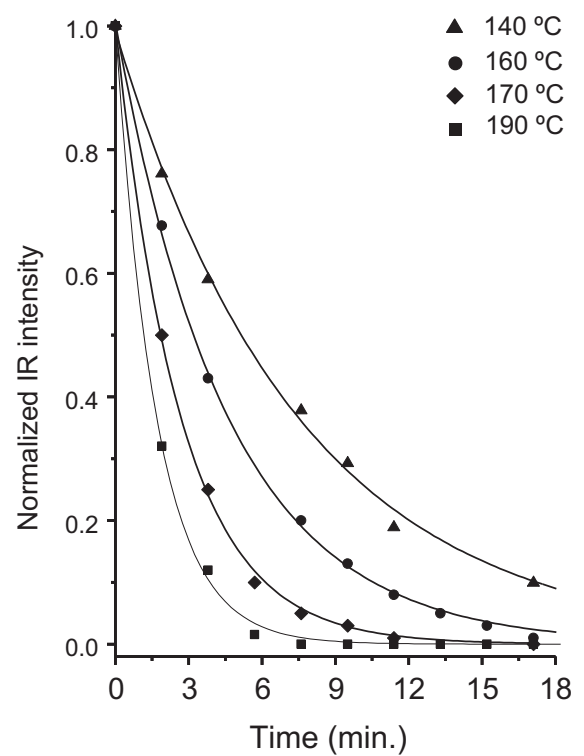

Fig. 3. Dependence of the normalized (to unity) integrated intensities of the CBID infrared bands in the 1640-1500 range and $\sim 1412 \mathrm{~cm}^{-1}$ with time. $T\left({ }^{\circ} \mathrm{C}\right): \boldsymbol{\Delta} 140$, 160, 170, 190.

Table 1

Rate constants for the CBID $\rightarrow$ CBIOD thermal isomerization at different temperatures

\begin{tabular}{ll}
\hline$T\left({ }^{\circ} \mathrm{C}\right)$ & $k\left(\mathrm{~s}^{-1}\right) \times 10^{4}$ \\
\hline 110 & $1.46 \pm 0.07$ \\
140 & $22.2 \pm 0.6$ \\
160 & $36.4 \pm 0.7$ \\
170 & $62.5 \pm 1.2$ \\
190 & $99.2 \pm 1.6$ \\
\hline
\end{tabular}

The Arrhenius plot shown in Fig. 4 allowed to obtain the activation energy of the CBID $\rightarrow$ CBIOD isomerization process, which was found to be $49.1 \pm 5.3 \mathrm{~kJ} \mathrm{~mol}^{-1}$. This value is similar, but slightly lower than those measured or estimated theoretically for concerted sigmatropic rearrangements in related compounds ${ }^{31}$ \{e.g., in allylcyclopentenyl ethers: ${ }^{32} 71.1-87.9 \mathrm{~kJ} \mathrm{~mol}^{-1}$ (in benzene solution), cyanosubstituted allyl-vinyl ethers: ${ }^{33} 92.0-117.2 \mathrm{~kJ} \mathrm{~mol}^{-1}$ (in diethyl ether), 5-allyloxi-1-phenyl-tetrazoles: ${ }^{19} 69.0-92.0 \mathrm{~kJ} \mathrm{~mol}^{-1}$ (in DMSO) or $82.0-103.8 \mathrm{~kJ} \mathrm{~mol}^{-1}$ (in tetrachloroethane)\}, in line with the above mentioned weakness of the $\mathrm{O}-\mathrm{C}_{\text {Allyl }}$ bond in the presently studied molecule. Moreover, the activation energy of the $\mathrm{CBID} \rightarrow \mathrm{CBIOD}$ isomerization is also somewhat lower than that previously determined for the analogous isomerization of the nonsubstituted allylic parent compound $\left(92.2 \pm 1.1 \mathrm{~kJ} \mathrm{~mol}^{-1}\right),{ }^{15}$ as it

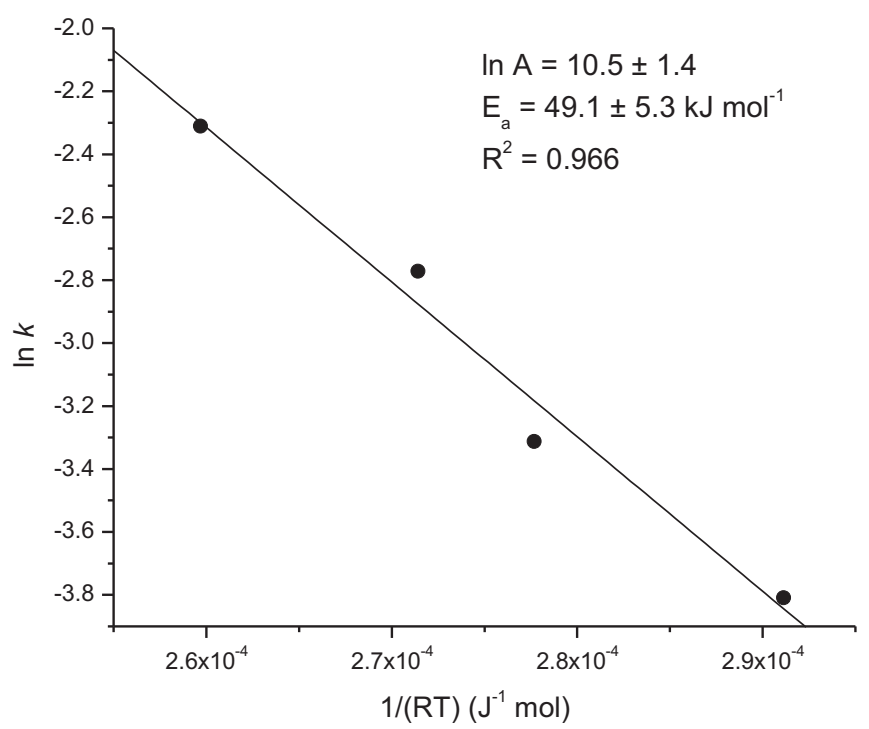

Fig. 4. Arrhenius plot of $\ln k$ versus $1 /(R T)$, yielding the activation energy $\left(E_{\mathrm{a}}\right)$ for the $\mathrm{CBID} \rightarrow$ CBIOD isomerization process.

could be expected taking into account the presence in CBID of the methyl substituent on the allylic system, which can stabilize a transition state for the symmetry-allowed general $\left[3,3^{\prime}\right]$ Cope rearrangement bearing a partially positive allylic moiety.

In line with the ease of the CBID $\rightarrow$ CBIOD isomerization to take place, is also the observation that, contrarily to what was found for the unsubstituted allyl saccharinate, ${ }^{15}$ this process does also occur at temperatures below the melting point of CBID, though under these conditions $\left(T=110^{\circ} \mathrm{C}\right)$ the rate constant was found to be one order of magnitude smaller (see Fig. 5 and Table 1). Note that the data shown in Fig. 5 for the solid state CBID $\rightarrow$ CBIOD conversion respect only to ca. $40 \%$ conversion of the reactant. For longer reaction times (greater than ca. $1 \mathrm{~h}$ ), the crystal of the reactant becomes distorted, and the obtained spectra were found to show significant intensity changes not ascribable to the isomerization process, which preclude the kinetic study of the reaction at later stages.

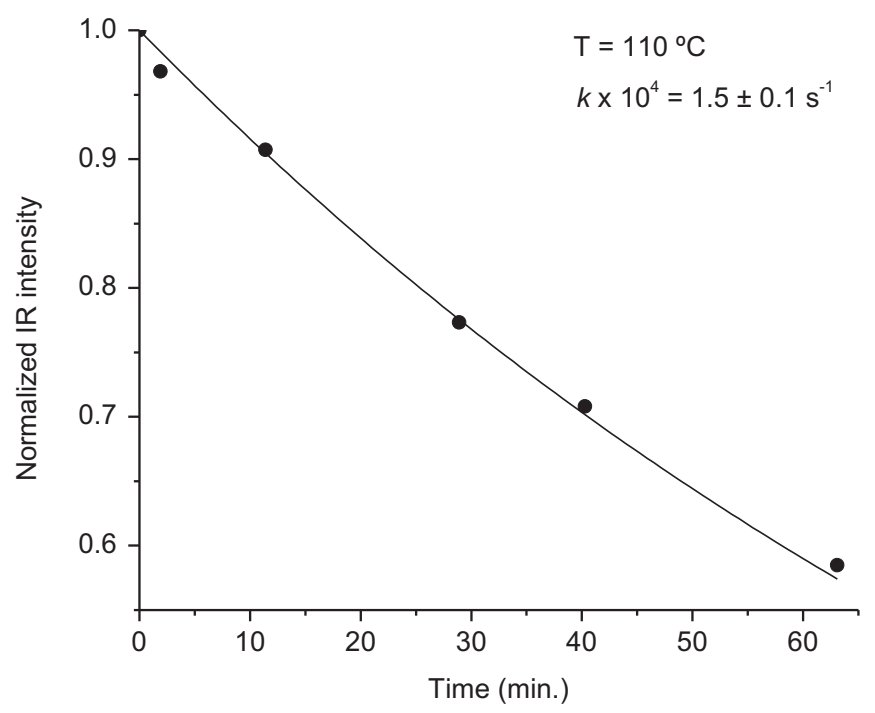

Fig. 5. Dependence of the normalized (to unity) integrated intensities of the CBID infrared bands in the $1640-1500$ range and $\sim 1412 \mathrm{~cm}^{-1}$ with time. $\left(T=110{ }^{\circ} \mathrm{C}\right.$; below the melting point of the reactant). 


\subsection{Differential scanning calorimetry (DSC) and polarized light thermomicroscopy (PLTM) experiments}

A typical DSC curve, obtained on heating pure CBID between $25^{\circ} \mathrm{C}$ and $215^{\circ} \mathrm{C}$, at a scanning rate $\beta=10^{\circ} \mathrm{C} \mathrm{min}-1$, is shown in Fig. 6 (a). Polarized light thermomicroscopy was also used in order to correctly interpret the signals observed in the DSC thermogram, as it allows sample visualization when submitted to a selected temperature program. The images shown in Fig. 7(a) are clear evidence that, at this scanning rate, no structural changes took place in the anisotropic crystalline material from $25{ }^{\circ} \mathrm{C}$ to about $130{ }^{\circ} \mathrm{C}$. At $130{ }^{\circ} \mathrm{C}$, CBID melting process begins and, at $134^{\circ} \mathrm{C}$, only the liquid phase (isotropic) is observed. Therefore, the endothermic peak in the DSC curve corresponds to the melting process. Fusion takes place at $T_{\text {fus }}=130.6 \pm 0.2^{\circ} \mathrm{C}$, with enthalpy $\Delta_{\text {fus }} H=25.8 \pm 0.2 \mathrm{~kJ} \mathrm{~mol}^{-1}$. The large exothermic peak registered between $135{ }^{\circ} \mathrm{C}$ and $200{ }^{\circ} \mathrm{C}$ corresponds to the compound isomerization, with $\Delta_{\mathrm{rx}} H=-27.0 \pm 0.8 \mathrm{~kJ} \mathrm{~mol}^{-1}$. The ${ }^{1} \mathrm{H}$ NMR spectrum obtained at room temperature for the product of the isomerization reaction, collected from the DSC pan, confirms it as the $\left[3,3^{\prime}\right]$-product (CBIOD). The numerical values presented are the mean of $n=6$ independent experiments, with the uncertainty expressed as one standard deviation.

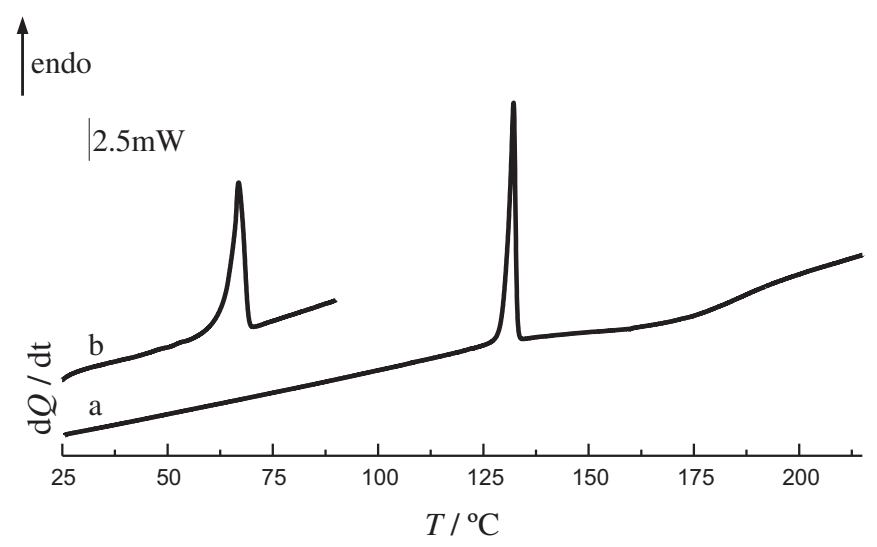

Fig. 6. DSC curves of heating runs: (a) CBID, $m=1.64 \mathrm{mg}$; (b) CBIOD, $\mathrm{m}=2.90 \mathrm{mg}$; $\beta=10{ }^{\circ} \mathrm{C} \mathrm{min}^{-1}$.

No crystallization was observed on cooling runs from $215{ }^{\circ} \mathrm{C}$ to $25^{\circ} \mathrm{C}$. Crystals were obtained in some DSC pans kept at room temperature for several months, which allowed the characterization of the
CBIOD fusion process, Fig. 6(b), at $T_{\text {fus }}=65.0 \pm 0.2 \quad{ }^{\circ} \mathrm{C}$ with $\Delta_{\text {fus }} H=17.5 \pm 0.5 \mathrm{~kJ} \mathrm{~mol}^{-1}, n=3$. The fusion process, observed by PLTM, of a small sample taken from one of those DSC pans is shown in Fig. 7(b). Before melting, no modifications were observed in the sample.

Additional PLTM experiments, with a lower temperature limit, allowed finding conditions to obtain room temperature crystalline CBIOD. On cooling the molten compound, vitrification occurs followed by cracking of the vitreous phase, (the isotropic cracked solid shown in Fig. 8, at $-84^{\circ} \mathrm{C}$ ). On heating (Fig. 8), devitrification is evident between -41 and $-38^{\circ} \mathrm{C}$ (as a consequence of this process that originates an undercooled liquid, the cracks obviously disappear) and cold crystallization begins at about $-11^{\circ} \mathrm{C}\left(\right.$ at $\left.\beta=10^{\circ} \mathrm{C} \mathrm{min}^{-1}\right)$, giving rise to the anisotropic $\mathrm{CBIOB}$ crystals, which melt at about $65^{\circ} \mathrm{C}$.

This procedure was then used to obtain crystalline CBIOD, whose room temperature infrared spectrum is presented in Fig. 9(a). The spectrum of the melted phase obtained by heating the crystal to $\sim 90^{\circ} \mathrm{C}$ is shown in Fig. 9(b). The obtained spectrum is, as expected, equal to that presented in Fig. 2 for a 30 min reaction time at $140^{\circ} \mathrm{C}$.

\section{Conclusions}

Temperature dependent infrared spectroscopy, differential scanning calorimetry, and polarized light thermomicroscopy were used to shed light on the thermally induced sigmatropic isomerization of neat pseudosaccharyl crotyl ether, 3-(E)-(but-2-enoxy)1,2-benzisothiazole 1,1-dioxide (CBID). Contrarily to what has been observed previously for the compound in solution ${ }^{13}$, the reaction taking place in both melted and crystalline phases was found to yield only the product resulting from the $\left[3,3^{\prime}\right]$ migration of the allylic system from $\mathrm{O}$ to $\mathrm{N}, 2-(E)-1$-methylprop2-en-1,2-benzisothiazol-3(2H)-one 1,1-dioxide (CBIOD). The enthalpy of reaction, determined by DSC, was found to be $\Delta_{\mathrm{rx}} H=-27.0 \pm 0.8 \mathrm{~kJ} \mathrm{~mol}^{-1}$. In the melt, the activation energy of the process was determined as being $49.1 \pm 5.3 \mathrm{~kJ} \mathrm{~mol}^{-1}$, with $k=(22.2 \pm 0.6) \times 10^{4} \mathrm{~s}^{-1}$ at $140^{\circ} \mathrm{C}$. In the solid state, at $110^{\circ} \mathrm{C}$, the rate constant drops by one order of magnitude $[k=(1.46 \pm 0.07) \times$ $10^{4} \mathrm{~s}^{-1}$. Easy crystallization of CBIOD from the vitrified compound upon heating was observed, allowing for its spectroscopic characterization in the crystalline phase and measurement of its melting point (ca. $65{ }^{\circ} \mathrm{C}$ ). Assignments were proposed for the infrared spectra of the observed neat condensed phases of the two compounds. (a)

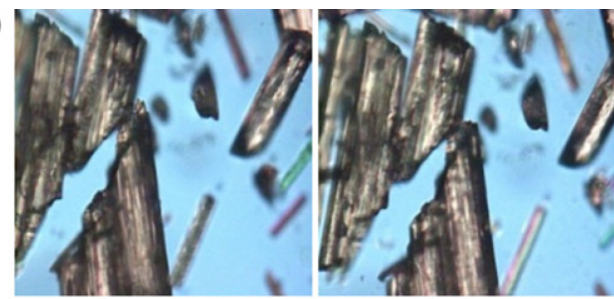

$25^{\circ} \mathrm{C}$ $130^{\circ} \mathrm{C}$

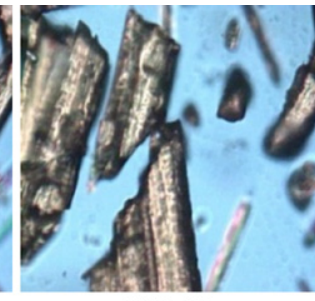

$132^{\circ} \mathrm{C}$

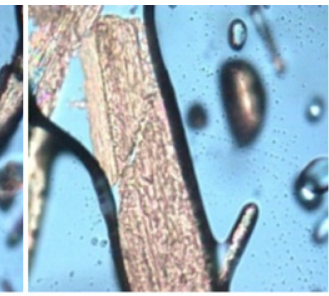

$133^{\circ} \mathrm{C}$

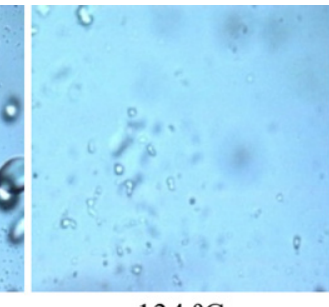

$134{ }^{\circ} \mathrm{C}$

(b)

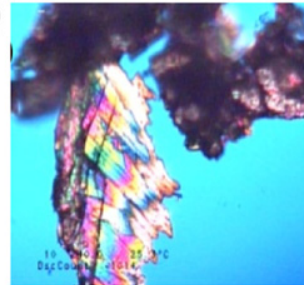

$25^{\circ} \mathrm{C}$

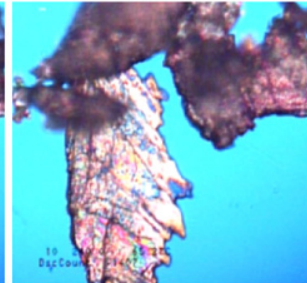

$64^{\circ} \mathrm{C}$

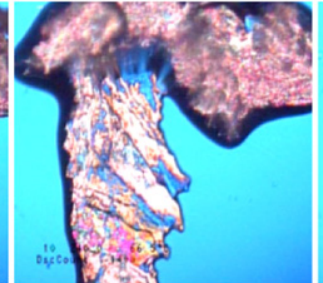

$65^{\circ} \mathrm{C}$

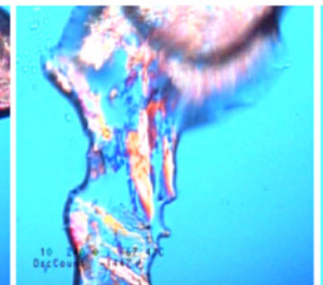

$66^{\circ} \mathrm{C}$

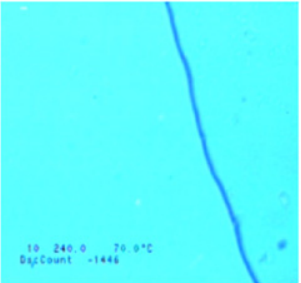

$69^{\circ} \mathrm{C}$

Fig. 7. PLTM images of heating runs: (a) CBID, (b) CBIOD, magnification $200 \times ; \beta=10{ }^{\circ} \mathrm{C} \mathrm{min}^{-1}$. 


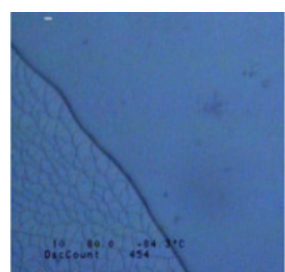

$-84^{\circ} \mathrm{C}$

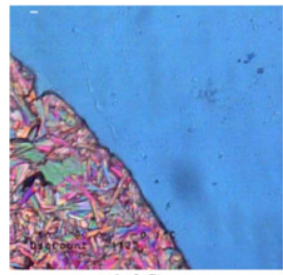

$0^{\circ} \mathrm{C}$

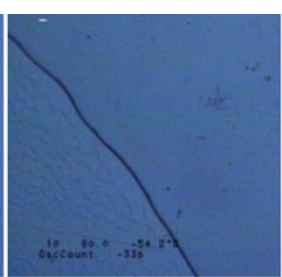

$-54^{\circ} \mathrm{C}$

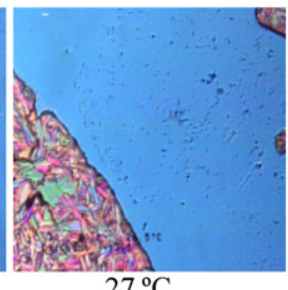

$27^{\circ} \mathrm{C}$

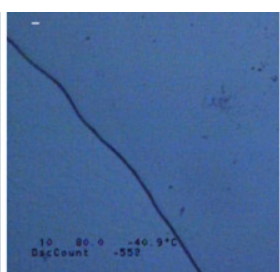

$-41^{\circ} \mathrm{C}$

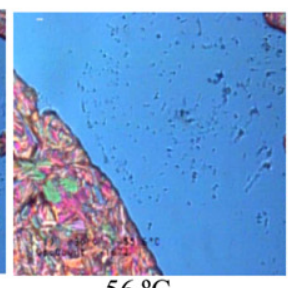

$56^{\circ} \mathrm{C}$

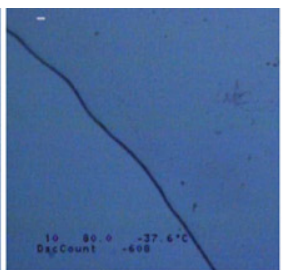

$-38^{\circ} \mathrm{C}$

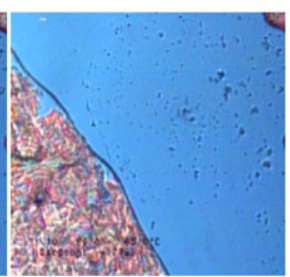

$65^{\circ} \mathrm{C}$

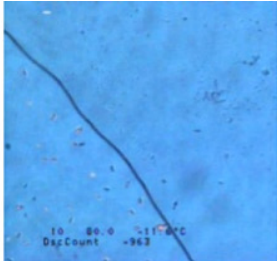

$-11^{\circ} \mathrm{C}$

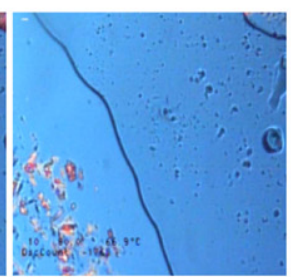

$67^{\circ} \mathrm{C}$

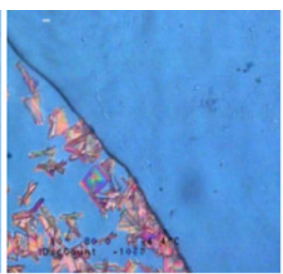

$-4^{\circ} \mathrm{C}$

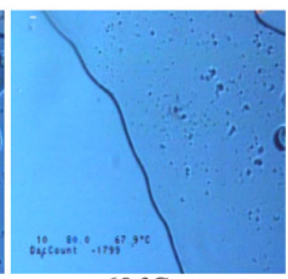

$68^{\circ} \mathrm{C}$

Fig. 8. PLTM images of a heating run of vitrified CBIOD; magnification $200 \times ; \beta=10{ }^{\circ} \mathrm{C} \mathrm{min}^{-1}$.

(a)

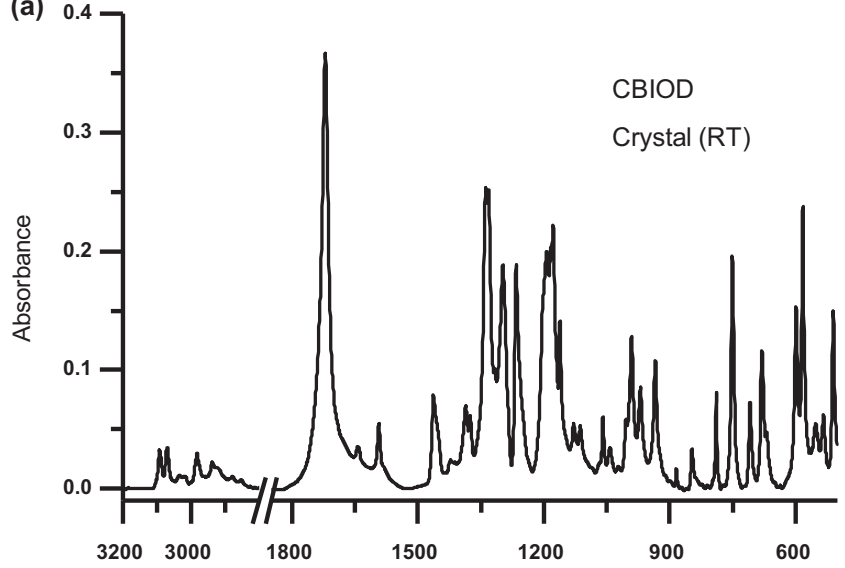

(b)

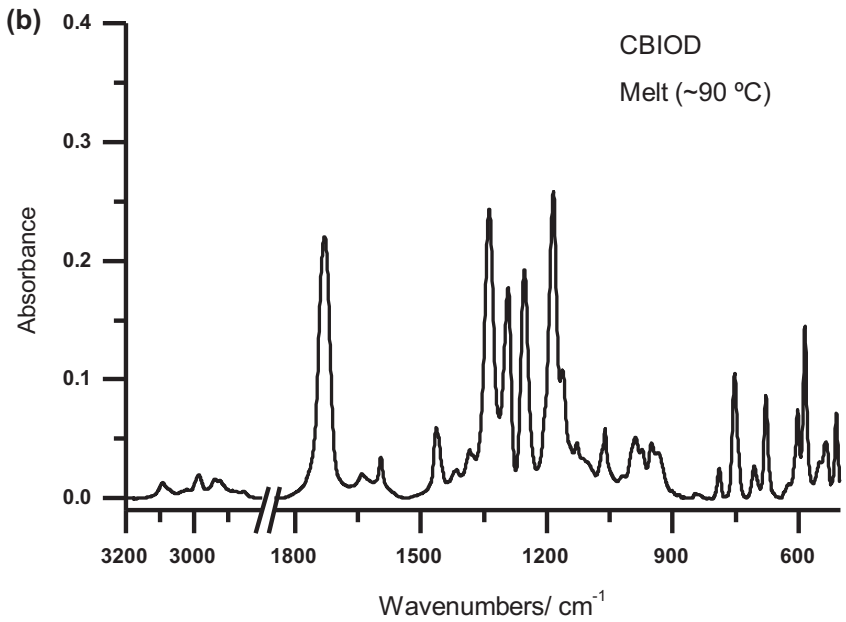

Fig. 9. Infrared spectra of CBIOD; (a) crystalline phase at room temperature. (b) Molten compound at $\sim 90{ }^{\circ} \mathrm{C}$; both in a $\mathrm{KBr}$ pellet.

\section{Experimental}

\subsection{Synthesis}

3-(E)-But-2-enoxy-1,2-benzisothiazole 1,1-dioxide (CBID) was synthesized from crotyl alcohol and freshly prepared saccharyl chloride as described below. The reaction produced a byproduct that was isolated, crystallized, and identified as dimethylamino-saccharin.
This compound results from reaction of triethylamine, used as an organic base in the etherification procedure, with saccharyl chloride, and indicates that saccharyl chloride is easily converted in a triethylammonium salt that subsequently forms the byproduct, possibly through elimination of chloroethane. Formation of the triethylammonium saccharin intermediate also indicates that cleavage of the $\mathrm{C}-\mathrm{Cl}$ bond in saccharyl chloride is relatively easy, although it forms a carbocation-like center on the saccharyl system, known for its electron-withdrawing capacity. This observation raises questions regarding the mechanism of etherification. The alcohol, a nucleophile, may attack the $\mathrm{sp}^{2}$-carbon of saccharyl chloride, affording an intermediate from which the chloride is eliminated to give the ether (addition-elimination mechanism). Alternatively, it may react with a carbocation-like center resulting from cleavage of the $\mathrm{C}-\mathrm{Cl}$ bond facilitated by triethylamine.

4.1.1. Saccharyl chloride (3-chloro-1,2-benzisothiazole 1,1-dioxide). Obtained from saccharin $(10.2 \mathrm{~g}, 56 \mathrm{mmol})$ and phosphorus pentachloride $(14.0 \mathrm{~g}, 66 \mathrm{mmol})$, heated at $180{ }^{\circ} \mathrm{C}$, as previously described. Crystallization from ethanol afforded the product as colorless needles ( $7.00 \mathrm{~g}, 63 \%$ yield), $\mathrm{mp} 143-145^{\circ} \mathrm{C}$ (lit. $143-145^{\circ} \mathrm{C}^{24}$ ). IR $\nu_{\max }\left(\mathrm{cm}^{-1}\right): 1724,1654,1603(\mathrm{C}=\mathrm{C}), 1346\left(\mathrm{SO}_{2}\right), 775(\mathrm{Ar}-\mathrm{H})$ and $692(\mathrm{C}-\mathrm{Cl}) ;{ }^{1} \mathrm{H}$ NMR $\left(\mathrm{CDCl}_{3}\right): \delta 7.85(4 \mathrm{H}, \mathrm{m}, \mathrm{Ar}-\mathrm{H})$. Found: $\mathrm{C}, 41.5 \%$; $\mathrm{H}, 2.0 \%$;, $6.9 \%$; calcd for $\mathrm{C}_{7} \mathrm{H}_{4} \mathrm{NO}_{2} \mathrm{SCl}$ : C, $41.7 \%$; $\mathrm{H}, 2.0 \%$;, $7.0 \%$. MS (EI), $m / z 201[\mathrm{M}]^{+}$.

4.1.2. 3-(E)-But-2-enoxy-1,2-benzisothiazole 1,1-dioxide (CBID). 3Chloro-1,2-benzisothiazole 1,1-dioxide (pseudosaccharyl chloride; $2.71 \mathrm{~g}, 13.46 \mathrm{mmol}$ ) was added to a mixture of crotyl alcohol $(1.25 \mathrm{~mL}, 1.06 \mathrm{~g}, 14.7 \mathrm{mmol})$ and triethylamine $(5 \mathrm{~mL})$ in toluene $\left(30 \mathrm{~mL}\right.$ ). The solution was stirred at $40{ }^{\circ} \mathrm{C}$ until the starting material had disappeared, as shown by TLC. The precipitate of triethylamine hydrochloride was filtered off and the filtrate was evaporated to give a yellow crystalline solid, which was re-crystallized from ethanol ( $2.2 \mathrm{~g}, 69 \%$ yield), mp $130-132{ }^{\circ} \mathrm{C}$ (lit. $\left.124-125{ }^{\circ} \mathrm{C}^{24}\right) .{ }^{1} \mathrm{H}$ $\operatorname{NMR}\left(\mathrm{CDCl}_{3}\right): \delta 7.89(1 \mathrm{H}, \mathrm{d}, J=7.3 \mathrm{~Hz}), 7.76(3 \mathrm{H}, \mathrm{m}), 6.03(1 \mathrm{H}, \mathrm{m})$, $5.83(1 \mathrm{H}, \mathrm{m}), 5.04(2 \mathrm{H}, \mathrm{d}, J=6.9 \mathrm{~Hz}), 1.83$ (3H, d, $J=6.3 \mathrm{~Hz})$. MS (EI), $\mathrm{m} / z 238[\mathrm{M}]^{+}$(see Figs. S1, S3, Supplementary data, for ${ }^{1} \mathrm{NMR}$ and mass spectra).

4.1.3. 2-(E)-1-Methylprop-2-en-1,2-benzisothiazol-3(2H)-one 1,1dioxide (CBIOD). 3-(E)-But-2-enoxy-1,2-benzisothiazole 1,1-dioxide ( $80 \mathrm{mg}, 0.34 \mathrm{mmol}$ ) was placed in a tube and heated neat in an oil bath at $130{ }^{\circ} \mathrm{C}$ for $45 \mathrm{~min}$. CBIOD was obtained as yellow oil $(0.56 \mathrm{~g}$, $70 \%$ yield $),{ }^{1} \mathrm{H}$ NMR $\left(\mathrm{CDCl}_{3}\right): \delta 8.03(1 \mathrm{H}, \mathrm{d}, J=7.0 \mathrm{~Hz}), 7.85(3 \mathrm{H}, \mathrm{m})$, $6.22(1 \mathrm{H}, \mathrm{m}), 5.40(1 \mathrm{H}, \mathrm{d}, J=17.1 \mathrm{~Hz}), 5.29(1 \mathrm{H}, \mathrm{d}, J=10.3 \mathrm{~Hz}), 4.91$ 
$(1 \mathrm{H}, \mathrm{m}), 1.72(3 \mathrm{H}, \mathrm{d}, J=7.1 \mathrm{~Hz}$ ) (see Figs. S2, S4, Supplementary data, for ${ }^{1} \mathrm{NMR}$ and mass spectra).

\subsection{Infrared spectroscopy}

The infrared spectra, in the $500-4000 \mathrm{~cm}^{-1}$ range, were recorded for the compound diluted in a $\mathrm{KBr}$ pellet, using a Thermo Nicolet IR300 FTIR spectrometer, resolution $1 \mathrm{~cm}^{-1}$, or a Bomem MB104 FT-spectrometer, with $4 \mathrm{~cm}^{-1}$ resolution, and either a SPECAC variable temperature infrared cell with an iron/constantan (copper-nickel) J-type thermocouple, connected to a digital controller (Shinho, MCD 530; accuracy ca. $\pm 2{ }^{\circ} \mathrm{C}$ ), or a modified DTA cell Mettler-Toledo FP90 thermosystem with a Pt100 precision sensor (accuracy $\pm 0.1^{\circ} \mathrm{C}$ ) (Figs. 1 and 2). The sample compartment of the spectrometer was purged during all experiments by means of a constant flux of dry nitrogen, to avoid contamination from absorptions due to atmospheric water and $\mathrm{CO}_{2}$.

\subsection{Differential scanning calorimetry (DSC) and polarized light thermo-microscopy (PLTM)}

DSC experiments were performed using a Perkin Elmer DSC7 calorimeter, with an intracooler cooling unit at $-10{ }^{\circ} \mathrm{C}$ (ethyleneglycol/water $1: 1 \mathrm{v} / \mathrm{v}$ cooling mixture). The samples were hermetically sealed in aluminum pans and as reference an empty pan was used. A $20 \mathrm{~mL} \mathrm{~min}{ }^{-1}$ nitrogen purge was employed. Temperature and enthalpy calibration were performed as in previous authors' work $^{32}$ with high-grade standards, namely, biphenyl (CRM LGC 2610, $T_{\text {fus }}=68.93 \pm 0.03{ }^{\circ} \mathrm{C}$ ) and indium (Perkin Elmer, $x=99.99 \%, T_{\text {fus }}=156.60{ }^{\circ} \mathrm{C}$ ). Enthalpy calibration was performed with indium $\left(\Delta_{\text {fus }} H=3286 \pm 13 \mathrm{~J} \mathrm{~mol}^{-1}\right)$. DSC curves were analyzed with Pyris software version 3.5.

The polarized light thermomicroscopy was performed in a Linkam DSC600 system attached to a DMRB Leica microscope fitted with polarized light facilities, connected to a Sony CCD-IRIS/RGB video camera. A Linkam system software with Real Time Video Measurement was used for image analysis. A small amount of the sample to be studied was placed in a $7 \mathrm{~mm}$ glass crucible used as a cell, which was covered with a glass lid. Thermal cycles were performed at $10^{\circ} \mathrm{C} \mathrm{min}^{-1}$, and the images obtained by combined use of polarized light and wave compensators at $200 \times$ magnification. Biphenyl and benzoic acid were used to confirm temperature accuracy.

\section{Acknowledgements}

The research was supported by the Portuguese Fundação para a Ciência e a Tecnologia, COMPETE and FEDER (Project PTDC/QUIQUI/1118779/2009). Authors thanks the Nuclear Magnetic Resonance Laboratory of the Coimbra Chemistry Centre (www.nmrccc.uc.pt), Universidade de Coimbra, supported in part by grant REEQ/481/QUI/2006 from FCT, POCI-2010 and FEDER, Portugal.

\section{Supplementary data}

${ }^{1}$ NMR and mass spectra for CBID and CBIOD (Figs. S1-S4) and proposed assignments for the full set of observed bands in IR spectra of both compounds (Tables S5, S6). Supplementary data related to this article can be found online at http://dx.doi.org/ 10.1016/j.tet.2012.10.100.

\section{References and notes}

1. , Otten, M.; von Deyn, W.; Engel, S.; Hill, R.; Kardorff, U.; Vossen, M.; Plath, P. Isoxazole-4-yl-benzoyl derivatives and their use as herbicides, Patent W09719076, Internationale Anmeldung Veroffentlicht nach dem Vertrag uber die Internationale Zusammenargeit auf dem Gebiet des Patentwesens. Weltorgani-sationfur Geistiges Eigentum, 1997.

2. Wepplo, P. J.; Rampulla, R. A.; Heffernan, G. D.; Cosette, M. V.; Diehl, R. E.; Fiordeliso, J. J.; Haley, G. J.; Guaciaro, M. A. Herbicidal 3-heterocyclic substituted benzisothiazole and benzisoxazole compounds, Patent WO0179203, Internationale Anmeldung Veroffentlicht nach dem Vertrag uber die Internationale Zusammenargeit auf dem Gebiet des Patentwesens. Weltorganisationfur Geistiges Eigentum, 2004.

3. Gravestock, M. B. Bicyclic heterocyclic substituted phenyl oxazolidinone antibacterials, and related compositions and methods, Patent WO/1999/10342. Internationale Anmeldung Veroffentlicht nach dem Vertrag uber die Internationale Zusammenargeit auf dem Gebiet des Patentwesens. Weltorganisationfur Geistiges Eigentum, 1999.

4. Eacho, P. I.; Foxworthy-Mason, P. S.; Lin, H. -S.; Lopez, J. E.; Mosior, M.; Richett, M. E. Benzisothiazol-3-one-carboxylic acid amides as phospholipase inhibitors, Patent WO/2004/094394. Internationale Anmeldung Veroffentlicht nach dem Vertrag uber die Internationale Zusammenargeit auf dem Gebiet des Patentwesens. Weltorganisationfur Geistiges Eigentum, 2004.

5. Hlasta, D. J.; Bell, M. R.; Court, J. J.; Cundy, K. C.; Desai, R. C.; Ferguson, E. W.; Gordon, R. J.; Kumar, V.; Maycock, A. L.; Subramanyam, C. Bioorg. Med. Chem. Lett. 1995, 5, 331.

6. Subramanyam, C.; Bell, M. R.; Ferguson, E.; Gordon, R. G.; Dunlap, R. P.; Franke, C.; Mura, A. J. Bioorg. Med. Chem. Lett. 1995, 5, 319.

7. Wang, L. H.; Yang, X. Y.; Zhang, X.; Mihalic, K.; Fan, Y. X.; Xiao, W.; Zack Howard, O. M.; Appella, E.; Maynard, A. T.; Farrar, W. L. Nat. Med. 2004, $10,40$.

8. Sharmeen, L.; McQuade, T.; Heldsinger, A.; Gogliotti, R.; Domagala, J.; Gracheck, S. Antiviral Res. 2001, 49, 101.

9. Johnstone, R. A. W.; Wilby, A. H.; Entwistle, I. D. Chem. Rev. 1985, 85, 129.

10. Araújo, N. C. P.; Brigas, A. F.; Cristiano, M. L. S.; Frija, L. M. T.; Guimarães, E. M. O.; Loureiro, R. M. S. J. Mol. Catal. A: Chem. 2004, 215, 113.

11. Frija, L. M. T.; Cristiano, M. L. S.; Guimarães, E. M. O.; Martins, N. C.; Loureiro, R. M. S.; Bikley, J. J. Mol. Catal. A: Chem. 2005, 242, 241.

12. Barkley, J. V.; Cristiano, M. L. S.; Johnstone, R. A. W.; Loureiro, R. M. S. Acta Crystallogr., Sect. C: Cryst. Struct. Commun. 1997, 53, 383.

13. Cristiano, M. L. S.; Brigas, A. F.; Johnstone, R. A. W.; Loureiro, R. M. S.; Pena, P. C. A. J. Chem. Res., Synop. 1999, 704.

14. Araújo, N. C. P.; Barroca, P. M. M.; Bickley, J. F.; Brigas, A. F.; Cristiano, M. L. S.; Johnstone, R. A. W.; Loureiro, R. M. S.; Pena, P. C. A. J. Chem. Soc., Perkin Trans. 1 2002, 1213.

15. Gómez-Zavaglia, A.; Kaczor, A.; Almeida, R.; Cristiano, M. L. S.; Eusébio, M. E. S.; Maria, T. M. R.; Mobili, P.; Fausto, R. J. Phys. Chem. A 2009, 113, 3517.

16. Almeida, R.; Gómez-Zavaglia, A.; Kaczor, A.; Cristiano, M. L. S.; Eusébio, M. E. S.; Maria, T. M. R.; Fausto, R. Tetrahedron 2008, 64, 3296.

17. Kaczor, A.; Proniewicz, L.; Almeida, R.; Gómez-Zavaglia, A.; Cristiano, M. L. S.; Matos Beja, A. M.; Ramos Silva, M.; Fausto, R. J. Mol. Struct. 2008, 892, 343.

18. Cristiano, M. L. S.; Johnstone, R. A. W.; Price, P. J. J. Chem. Soc., Perkin Trans. 1 1996, 1453.

19. Cristiano, M. L. S.; Johnstone, R. A. W. J. Chem. Soc., Perkin Trans. 2 1997, 489.

20. Cristiano, M. L. S.; Johnstone, R. A. W. J. Chem. Res. 1997, 164

21. Frija, L. M. T.; Reva, I.; Ismael, A.; Coelho, D. V.; Fausto, R.; Cristiano, M. L. S. Org. Biomol. Chem. 2011, 9, 6040.

22. Woodward, R. B.; Hoffmann, R. The Conservation of Orbital Symmetry; Chemie GmbH: Weinheim, 1970.

23. Ito, H.; Tagushi, T. Chem. Soc. Rev. 1999, 28, 43

24. Zipse, H. H. J. Chem. Soc., Perkin Trans. 2 1996, 1797.

25. Birney, D. M.; Xu, X.; Ham, S. Angew. Chem., Int. Ed. 1999, 38, 189.

26. Pauling, L. J. Am. Chem. Soc. 1947, 69, 542.

27. Handbook of Chemistry \& Physics; Lide, D. R., Ed.; CRC: Boca Raton, 1993-94; pp 9-1-9-41.

28. Bürgi, H. B.; Dunitz, J. D. Acc. Chem. Res. 1983, 16, 153.

29. Gómez-Zavaglia, A.; Kaczor, A.; Almeida, R.; Cristiano, M. L. S.; Fausto, R. J. Phys. Chem. A 2008, 112, 1762.

30. Gómez-Zavaglia, A.; Kaczor, A.; Coelho, D.; Cristiano, M. L. S.; Fausto, R. J. Mol. Struct. 2009, 919, 271.

31. Coates, R. M.; Rogers, B. D.; Hobbs, S. J.; Peck, D. R.; Curran, D. P. J. Am. Chem. Soc. 1987, 109, 1160.

32. Burrows, C. J.; Carpenter, B. K. J. Am. Chem. Soc. 1981, 103, 6983.

33. Maria, T. M. R.; Castro, R. A. E.; Bebiano, S. S.; Ramos Silva, M.; Matos Beja, A.; Canotilho, J.; Eusébio, M. E. S. Cryst. Growth Des. 2010, 10, 1194. 